\title{
Sleep duration and lymphocyte subsets profile in European adolescents. The HELENA Study
}

\author{
F. Perez de Heredia ${ }^{1}$, M. Garaulet ${ }^{2}$, S. Gómez-Martínez ${ }^{1}$, L. E. Díaz ${ }^{1}$, A. M. Veses ${ }^{1}$, C. Breidenassel ${ }^{3}$, \\ M. Ferrari ${ }^{4}$, F. Gottrand ${ }^{5}$, A. Kafatos ${ }^{6}$, Y. Manios ${ }^{7}$, D. Molnár ${ }^{8}$, L. A. Moreno ${ }^{9}$, M. Sjöstrom ${ }^{10}$, \\ K. Widhalm ${ }^{11}$ and A. Marcos ${ }^{1}$, on behalf of the Helena Study Group \\ ${ }^{1}$ Immunonutrition Research Group, ICTAN-CSIC, Madrid, Spain, ${ }^{2}$ Faculty of Biology, University of Murcia, Spain, \\ ${ }^{3}$ University Polytechnic of Madrid, Spain, ${ }^{4}$ Istituto Nazionale di Ricerca per gli Alimenti e la Nutrizione (INRAN), Rome, \\ Italy, ${ }^{5}$ University of Lille, France, ${ }^{6}$ University of Crete School of Medicine, Heraklion, Crete, Greece, ${ }^{7}$ Harokopio \\ University, Athens, Greece, ${ }^{8}$ University of Pécs, Hungary, ${ }^{9}$ University of Zaragoza, Spain, ${ }^{10}$ KarolinskaInstitutet, Stockholm, \\ Sweden, ${ }^{11}$ Medical University of Vienna, Vienna, Austria
}

Insufficient sleep is associated with higher incidence of infections and worse recovery, and more recently with increased risk for noninfectious diseases and low-grade inflammation ${ }^{(1)}$. The immune system seems to be strongly influenced by the sleep/wake cycle and has its own circadian rhythm, in both its functions and circulating cell numbers ${ }^{(2)}$. During adolescence sleep patterns experience significant changes, such as delay of sleep initiation and/or reduction of the sleep duration; therefore, sleeping habits at this period may have an impact on the immune system.

In the present work, absolute and relative counts of leukocyte types and lymphocyte subsets were compared between adolescents reporting to sleep less than 8 hours per night (short-sleep group) and those reporting 8 hours or more (sufficient sleep). Blood samples were collected after an overnight fast from 1,089 boys and girls (12.5-17.5 years old; $53.3 \%$ females) participating in the HELENA-CSS (Healthy Lifestyle in Europe by Nutrition in Adolescence-Cross-Sectional Study). Leukocyte and lymphocyte subset counts were compared by means of analysis of covariance (ANCOVA), adjusting for country, gender, Tanner stage and body mass index (BMI). Non-normally distributed variables were previously log-transformed.

Adolescents in the short-sleep group $(<8 \mathrm{~h} /$ night $)$ presented higher counts and percentages of total $\mathrm{T}\left(\mathrm{CD} 3^{+} ; P<0.05\right)$ and helper $\mathrm{T}$ $\left(\mathrm{CD} 4{ }^{+} ; P<0.01\right)$ lymphocytes, higher counts of total memory $\mathrm{T}$ cells $\left(\mathrm{CD} 3{ }^{+} \mathrm{RO}^{+} ; P<0.05\right)$ and memory helper $\mathrm{T}$ cells $\left(\mathrm{CD} 4{ }^{+} \mathrm{RO}^{+}\right.$; $P<0.001)$, and lower percentages of natural killer cells $\left(\mathrm{CD} 3^{-} \mathrm{CD} 16^{+} 56^{+} ; P<0.05\right)$, independently of gender and BMI.

Our results show a significant relationship between sleep duration and immune parameters in European adolescents, suggesting that sleep-related immune alterations can start at early life stages.

1. Faraut B, Boudjeltia KZ, Vanhamme L \& Kerkhofs M. Sleep Med Rev (2012) 16(2), 137-149.

2. Besedovsky L, Lange T \& Born J. Pflugers Arch - Eur J Physiol (2012) 463(1), 121-137. 